Studia UBB 刃ligitalia, Volume 62 (LXII) 2017, June, Issue 1, 9-25

Published Online: 2017-06-30

DOI:10.24193/subbdigitalia.2017.1.01

\title{
Digital documentary editing of St Patrick's epistles. Linking the manuscript witnesses to the canonical text
}

\author{
Roman Bleier \\ Karl-Franzens-University of Graz, Centre for Information \\ Modeling - Austrian Centre for Digital Humanities, Austria, \\ E-mail: roman.bleier@uni-graz.at
}

\begin{abstract}
St Patrick of Ireland, the fifth-century missionary and bishop, wrote two epistles which are commonly referred to as Confessio and Epistola ad milites Corotici. These two texts survive in seven medieval manuscript witnesses which were copied centuries after Patrick's time. This article discusses digital transcriptions of these manuscript witnesses. The transcriptions were encoded using the encoding standard of the Text Encoding Initiative (TEI) following a documentary editing approach. The transcriptions will be the core of a new digital documentary edition. This edition is meant to be a research tool for the exploration of the medieval documents, but at the same time it is a mediator between the manuscript witnesses and existing text-critical editions and translations of the texts. This mediator function is achieved by including markers of lines and chapter of a canonical edition and links to an existing text-critical edition online. In the final section a few examples will briefly be look at that illustrate what kind of analysis will be possible and what visual presentations of the transcriptions will be incorporated in the new edition.
\end{abstract}

Keywords: Text encoding; TEl; Canonical; Manuscripts; Text; Edition; Document; Patrick of Ireland.

\section{Introduction}

This article will discuss the development of digital transcriptions of the manuscript witnesses of St Patrick's epistles which are the core element of a Digital Documentary Edition currently developed at the University of Graz. The idea to create such transcriptions 
was conceived during work on the Saint Patrick's Confessio Hypertext Stack website, a digital scholarly editing project of the Royal Irish Academy that makes numerous resources related to the historical St Patrick available to the general public including images of the manuscript witnesses, text critical editions and translations. Transcriptions of the manuscript witnesses are not part of the Saint Patrick's Confessio Hypertext Stack as the primary focus of this project was on Ludwig Bieler's text-critical edition of Patrick's epistles and, therefore, the new edition will augment the already existing online resources. However, to think of the new edition simply as a add-on to the HyperStack is not correct. As will be argued later, the new edition will be a tool that is based on documentary model and addresses different research questions related to medieval text structure. Besides this documentary focus, the edition also understands itself as a mediator between the manuscripts and text-critical editions to provide a more holistic understanding of the manuscript evidence in the context of text-critical research. The resources of the Saint Patrick's Confessio Hypertext Stack are central and referenced and linked to in various ways in the new edition.

The manuscript witnesses were transcribed and enriched with metadata during a PhD project at Trinity College Dublin for which the Digital Arts and Humanities (DAH) programme provided funding and support. The Marie-Curie Initial Training Network DiXiT and the University of Graz provided further funding for the revision of the encoding model and the development of the edition. The electronic transcriptions were developed following the latest recommendations of the Text Encoding Initiative (TEI) and with a documentary editing approach in mind. The purpose of this article is it to discuss the rationale and the methodology behind the transcriptions project and to point at some possible use cases in the forthcoming digital edition. A particular challenge is the integration of both the diplomatic manuscript view and the canonical text structure used in print editions. It will be discussed later how this is achieved in the encoding model and in the web presentation.

\section{Exploring the manuscript witnesses}

St Patrick of Ireland is a popular saint who is especially well-known for the celebrations around the day of his presumed death on March 17. Patrick was a historical personage and a writer of letters, two which survive today. These are the two epistles known as Confessio and the Epistola ad milites Corotici (Bieler), and are variously referred to in what follows as Patrick's writings, Patrick's letters, or Patrick's epistles.

The Epistola ad milites Corotici, or short Epistola, is a letter pronouncing excommunication against a certain Coroticus and his men for raiding one of St Patrick's Christian communities, while the Confessio is a text with a strong autobiographical tendency in which Patrick tries to justify his life's work and his mission against accusations 
from other church men, in that sense, an apologia pro vita sua. Patrick's epistles are very important historical texts. They are the only reliable sources for the life of the historical Patrick and for his Christian mission to Ireland, and they are two of the few surviving contemporary texts that inform our knowledge of fifth-century Irish and British history (O'Loughlin). Furthermore, his epistles also have much to reveal about mobility, of people and ideas, shedding light in particular on the importation of ideas from the Roman empire into Ireland.

One problem presented by Patrick's letters as a source is that his original letters have not survived and the medieval manuscript witnesses contain different versions of his texts. The earliest surviving copy of the Confessio dates to the first decade of the ninth century (ca. 807), and is found in the Book of Armagh, now Ms 52 in the library of Trinity College Dublin. Not only is this the oldest manuscript witness, but it is the only surviving Irish manuscript, containing Patrick's writings (albeit only one of the two, namely an abbreviated version of Patrick's Confessio). Besides this Irish manuscript witness, there are three surviving manuscript witnesses from northern France, and three from England. These all date from the tenth to the thirteenth century and contain a much longer version of the Confessio and also Patrick's other text, the Epistola ad milites Corotici (Bieler).

The editors White and Bieler proposed that the manuscript witnesses form two groups based on their linguistic and codicological characteristics. The first (or Irish) group consists only of one manuscript, the Confessio-text in the Book of Armagh. The six other manuscript witnesses form a second group of manuscripts of continental and English origin. The most significant differences between the two groups of manuscripts can be summarized in five points (Bleier Re-Examining the Function of St Patrick's Writings in the Early Medieval Tradition):

1. Irish vs. non-Irish manuscripts.

2. Codex composition: the Irish copy of the Confessio survived in a collection of texts related to St Patrick.

3. Age: the Irish manuscript is the earliest to survive.

4. Shorter version of Confessio in the Irish group.

5. No Epistola in the Irish group.

From a text-critical and content point of view the last two points in the above list are in particular relevant. The Irish manuscript witness in the Book of Armagh contains one of the most reliable readings, however, substantial parts of the text of the Confessio and the entire Epistola are missing in this manuscript. This is a problem as this witness has great value for the reconstruction of the text. In the nineteenth and early twentieth century some scholars argued even that the shorter Book of Armagh version was the full Confessio text of St Patrick and the longer versions found in the other 
manuscripts are the product of the merging of two or three different letters of Patrick (Bleier Re-Examining the Function of St Patrick's Writings in the Early Medieval Tradition). While this argument has been widely refuted today, the Book of Armagh Confessio is central to a text-critical reconstruction of the text. Furthermore, it is an important document that gives insight into how the epistle was perceived and used in early medieval Ireland (Binchy 41-43) and is key to the understanding of the composition of the Patrician section in the Book of Armagh (Sharpe).

The diversity of the manuscript witnesses and the amount of text that is actually missing in some of them is one reason why a documentary edition is important. Some editors in the past have attempted to make the textual differences between the long and the short Confessio version visible by highlighted the parts of the text not available in the Irish manuscript (Dumville). The digital edition developed by the author goes even further and provides electronic transcriptions that can be compared in an automated way. Not only is it possible to see where text is and is not available, but also how the text was structured and presented in the manuscripts.

\section{Medieval and canonical text structure}

St Patrick's epistles have been published in print since the seventeenth century in editions, transcriptions and translations of varying quality. The variant readings of all seven medieval manuscript witnesses were first published by White in 1905 (Libri Sancti Patricii: The Latin Writings of Saint Patrick) ${ }^{1}$. White's edition has been certainly one of the most important and influential editions in Patrician studies. It has been credited to be the first truly text-critical edition (Bieler 30) as White used existing print editions with caution and applied a solid editing methodology. White also created a new chapter structure for Confessio and Epistola. White's page layout and structure, 62 short chapters for the Confessio and 21 for the Epistola, was later adopted by other editors and translators and is still used today. The mid-twentieth century edition by Bieler uses even White's page and line numbers as anchor points for apparatus and commentary. Since White's time other important print editions were presented by Bieler, Hanson, Hood and others. All these editions follow a text-critical approach and all use White's chapter organisation. Therefore, White's chapter organisation will also be called canonical chapter structure later in this article.

While the focus of interest was traditionally on the content and the reconstruction of the text of St Patrick's original epistles, in recent years more attention has been on text structure. A ground-breaking study exploring the possible text structure of the

\footnotetext{
1 White's first edition from 1905 was based on six manuscript witnesses (the Paris manuscript was missing). However, in the same year he published an article discussing the readings of the Paris manuscript and correcting his earlier edition (The Paris Manuscript of St. Patrick's Latin Writings).
} 
original epistles was presented by Howlett in 1994 in form of an edition per cola et commata. The edition revealed that Patrick used rhetorical devices and text structure similar to the one found in the bible. While Howlett's edition focuses on St Patrick's fifth-century texts, it triggered an ongoing discussion about text structure. The manuscript witnesses have only to a limited extent been part of this discussion. One reason being that a systematic study of layout and text structural features of the manuscripts is still missing.

Two editions that have been produced in the last decade try to make the manuscript witnesses better accessible. A key feature to make the manuscript witnesses better accessible is to somehow link transcriptions or facsimile images to the canonical chapter organisation used in most print editions. Freeman tried this by presenting his transcriptions following the canonical chapter structure rather than the layout of the manuscript witnesses. This is an interesting approach, but his transcriptions have some limitations what makes the comparison of different manuscript versions and text-critical editions cumbersome. For instance, Freeman does neither provide marker for line breaks of the manuscripts nor does he indicate the canonical line breaks and this makes granular comparison of the transcriptions very difficult. Another limitation is that Freeman focused primarily on the text of the manuscript witnesses and did not sufficiently record some features of the manuscripts such as the layout and abbreviations which are be central to a documentary edition.

Another approach to link the canonical text of an edition with the manuscript witnesses was realised in context of the already mentioned Saint Patrick's Confessio Hypertext Stack. The central component of the Saint Patrick's Confessio Hypertext Stack is a digital edition of Bieler's text-critical print edition. An additional feature is that the individual chapters of St Patrick's Confessio and Bieler's apparatus criticus are linked to facsimile images of the manuscripts. However, the possibility for comparison across different versions is again limited as the linking between the manuscript images and the text-critical edition happens on a folio and chapter level. Freeman's edition and the Saint Patrick's Confessio Hypertext Stack go some way towards providing better access to the manuscript witnesses. The new edition tries to overcome some of the limitations these editions have, providing a tool for the study of the manuscript witnesses on the one hand and on the other hand a better interface between canonical text structure and the manuscripts.

\section{A documentary encoding model}

The central component of the new edition are transcriptions of the seven medieval manuscript witnesses of Confessio and Epistola ad milites Corotici transcribed from high-resolution manuscript images and enriched with meta-information using XML 
following the recommendations of the TEI. The abbreviation TEI stands both for an encoding standard for electronic texts, Text Encoding for Interchange, or for the consortium that releases and continuously develops this standard, the Text Encoding Initiative. The TEI consortium was established in 1987 as an international research project to develop a standard to 'facilitate the creation, exchange, and integration of textual data in machine-readable form'. The goal was to create a standard that would support the encoding of 'all kinds of texts, in every human language, from every historical or social context'. Since its first release the TEI has become the de-facto standard for the encoding of humanities data. ${ }^{2}$

A documentary (or document-centred) editing approach focuses primarily on the accurate reproduction of historical documents such as the manuscript witnesses of St Patrick's epistles. This is distinct from a text-critical approach which focuses on the recreation of the original work of an author (e.g. the text of Patrick's fifth-century original epistles). Documentary editing is nothing new and has already been done in a print environment in the form of diplomatic, ultra-diplomatic and genetic editions long before the invention of electronic computers, John Gwynn's diplomatic transcription of the Book of Armagh is a good example. However, the majority of print editions in the nineteenth and twentieth centuries did not use such an editing approach. The reasons were that editors were primarily interested in the content of texts and less in the manuscript contexts texts survived in. Furthermore, advances in photography and facsimile editions questioned the value of ultra-diplomatic transcriptions. After all, high-quality photographs of a manuscript are a more accurate reproduction than a transcription can be. With advances in digital scholarly editing the view on documentary editing changed. Editors started to provide diplomatic transcriptions of manuscripts in order to interlink them with images and electronic editions put facsimile image and a reading text side-by-side. Pierazzo has pointed out that we should make a clear distinction between traditional diplomatic transcription and the semantically enriched digital transcriptions and she suggested the term Digital Documentary Edition (A rationale of digital documentary editions). This new generation of diplomatic transcriptions/editions goes far beyond its print predecessors and depending on one's research question a semantically enriched transcription can be a 'very powerful and versatile tool' (Digital Documentary Editions and the Others).

The new edition of St Patrick's epistles follows a documentary approach in the encoding and presentation of the transcriptions. The goal is a Digital Documentary Edition that is on the one hand a tool for the closer study of medieval text structure and scribe related features of the manuscript witnesses. Consequently, the TEI encoding model focuses first of all on the physical and topographic structure of the document:

\footnotetext{
${ }^{2}$ See: http://www.tei-c.org/index.xml.
} 
manuscript witness, folio, page, column and line. The encoding of these features was not always easy in TEl. Until recently the representation of the logical structure of a text, such as book, chapter, paragraph, etc., or the representation of a criticalapparatus was much better supported than material properties of a manuscript and topographic layout of the text. For instance, for a long time the TEI had no specialised element for the tagging of topographic lines while elements existed for the representation of sentences and verse lines. Some scholars successfully argued for the extension of the TEI to provide more flexibility for the development of documentary and genetic editions (Pierazzo and Stokes). The most substantial change in that direction happened in 2011 with the release of TEI P5 2.0. ${ }^{3}$ The transcriptions of St Patrick's manuscript witnesses take advantage of some of these new TEl elements such as <sourceDoc>, <surfaceGrp>, <surface>, <zone> and <line> to represent a documentary model of the manuscripts. The <sourceDoc $>$ contains the entire transcription of a manuscript witness. The <surfaceGrp> element groups folios together and the text of individual pages is transcribed within a <surface> element. Further topographic regions such as columns were encoded within a <zone> element with an attribute @type specifying the feature that was captured. Finally, within the different major zones the <line> element is used to tag topographic lines.

\section{Encoding structural elements of the manuscript witnesses}

Besides the above discussed topographic features a number of features were encoded that might have been used by the medieval scribes to implement some sort of a text structure. For instance, the incipit and explicit, where present, and the decorated initial are indicators for the beginning and end of a text such as the Confessio or the Epistola. It is important that these features are included in the transcription as they give us an important clue about how the texts were perceived by the copying scribe (Bleier Re-Examining the Function of St Patrick's Writings in the Early Medieval Tradition). Additionally a number of features were encoded that function as indicators of internal text structure implemented by the medieval scribe. Special attention was given to the recording of highlighted characters, punctuation and differing spaces between the words.

Within the text highlighted initials (often in combination with punctuation and/or a big space) are in many cases a sign for the start of some sort of a textual division identified by the medieval scribe. The Irish manuscript witness in the Book of Armagh is an interesting case as the scribe uses a very dense script with numerous ligatures, sub- and superscript characters and abbreviations. Furthermore, sections within the text are initialised not simply be a highlighted character, but by a feature

\footnotetext{
${ }^{3}$ See: http://www.tei-c.org/release/doc/tei-p5-doc/readme-2.0.html.
} 
called a 'diminuendo'. This is a common feature of early Insular manuscripts. The characteristic of a diminuendo is that the first few characters of a word, often the first word in a sentence, are bigger than the rest of the text. The biggest character is the first character in the word and every succeeding character is written in decreasing size. The Confessio text in the Book of Armagh has such a diminuendo at several points in the manuscript. Highlighted characters and the diminuendo are encoded using the $\mathrm{TEI}<\mathrm{hi}>$ to indicate that these characters are highlighted in some way. TEI allows to specify the form of highlighting by using @rend which may contain a description of how the text is rendered.

For the tagging of punctuation the TEI has a specialised element, the <pc> element. This element is also used in the transcriptions for the recording of various forms of text-structural punctuation. On the <pc> element an @type is provided to assign a standardised name for the punctuation in question (e.g. <pc type="period">.</pc>). In the case of a punctus or period the encoding is quite simple, because the Unicode character 'full stop' is used. This character is a standard Unicode character and part of the Basic Latin Unicode code range. However, not all punctuation characters used in medieval manuscripts have a standardised Unicode mapping - punctus elevatus or punctus interrogativus are such examples. For these characters it would be possible to use Unicode mappings supplied by work groups such as the Medieval Unicode Font Initiative (MUFI) for representation. In these cases the $\langle g\rangle$ element with an @ref is used within the element $\langle\mathrm{pc}>$ to link to a description of the character in the TEI header section where the element <charDecl> declared this non-standard characters and provides a set of specialised childelements that allow for the description of the character in question. Within <charDecl> an optional Unicode mapping such as the MUFI character declaration for the above mentioned punctus elevatus can be assigned to a character. In the assignment of $\mathrm{xml}$ :ids for non-standard characters the MUFI recommendations were followed.

The last text-structural feature that was encoded are spaces between the words.

The study of word separation and spaces between words is an important matter in early medieval manuscripts as spaces are sometimes used as indicators of text structure but at the same time they are used inconsistently and it is not always the case the what we would consider to be a word today is indeed delimited by spaces (Saenger 32-36). In the manuscript witnesses of St Patrick's writings spaces between the words fall roughly into one of three categories: no space, normal space, large space. All manuscript witnesses show a high degree of word separation. The later manuscripts even have features which are signs of high awareness of word separated manuscripts, such as the traits d'union or the 'accented double ii'. However, all manuscript witnesses contain occasional irregular spacing. Interestingly, the ninth-century manuscript from Dublin, the oldest manuscript, and the twelfth-century manuscript 
from Arras, one of the youngest manuscripts, show the highest level of word separation. In contrast, the eleventh-century manuscript from London has longer passages in 'aerated' script with irregular spacing.

In the digital transcriptions the TEI <space> element is used to record spaces between words and the attribute @quantity is used to record the quantity of space. However, because the manuscript witnesses come from different cultural backgrounds and time contexts the question of how to measure space is quite problematic. The size of spaces, whether between words or not, depends greatly on the format of the manuscript and the script used by the scribe. For instance, the Dublin manuscript (=Book of Armagh) is in size, script and layout very different from the Paris manuscript. The Dublin text is in a codex the size of a pocket gospel, written in narrow, very compact Insular script on pages with two-column layout, while on the other hand the Paris text is written in Carolingian minuscule on one-column pages in a script with more generous spacing and character width. Consequently, the measurement of spaces has to be relative to the context in which they are found rather than being absolute. Therefore, it was decided to use the average height of minims - the vertical strokes of the characters $m, n, u$ and $i-$ as a unit of measurement. To apply this measurement consistently a grid overlay was used over the manuscript images. However, even with a grid overlay the measurement of spaces was not always straightforward. Sometimes it is difficult to decide if there is a space and how big it really is.

Besides text structural features also a number of 'scribal accidentals' such as additions, deletions, substitutions and abbreviations were tagged using suitable TEI/XML elements. The advantage of TEI encoded transcriptions over print editions can be demonstrated very well with the encoding of abbreviations. The abbreviated form of a word is rarely incorporated into scholarly print editions. Editors usually provide a 'reading text' rather than a replication of the abbreviation. Sometimes the abbreviated word is highlighted in italics. This certainly makes sense, because correctly resolving of abbreviations requires a high level of linguistic and palaeographical knowledge about a manuscript and the text it contains. Consequently, simply reproducing abbreviations would make an edition as difficult to use as the original manuscript. However, abbreviations are an important feature of a scribe's copying style and therefore recording it may be useful to answer specific research questions. For instance, questions related to a scribe copying habits. Electronic text encoding with TEl allows both the abbreviated and the expanded form of a word to be equally recorded. This is done using the $<$ choice> element. For example within the <choice> element both forms the abbreviation uri and the expansion uestri can be recorded using the <abbr> element (for the abbreviated form) and the <expan> element (for the expanded form). Additionally, may the abbreviation marker and the part that was expanded by the editor be tagged. 
Such a TEI encoding allows for the presentation of different forms of an abbreviated word and additionally are the abbreviations searchable and can be statistically analysed across the manuscripts.

\section{Including markers of the canonical numbering}

Texts can be structured in different ways. The two text structures important for this project are the topographic text structure which follows the text-bearing material object and the semantic text structure which provides structure for the content of a text structuring using elements such as headings, sections and chapter. In the previous section the encoding of the topographic text structure was discussed. Furthermore, the encoding of text structural marker in the medieval manuscripts. These marker were included by the medieval scribes and represent the semantic structure of the text as understood by the medieval scribes. However, this is a different semantic structure than is found in recent editions and translations of St Patrick's epistles. In editions and translations the chapter structure introduced by White is used. Due to their wide adoption and the historical importance of White's edition, the chapter number introduced by him can be called canonical numbers and White's chapter structure the canonical text structure of the epistles.

The Functional Requirements for Bibliographic Records (FRBR) model can be used to describe the different levels on which these text structures operate (Kalvesmaki). FRBR is a model developed in a library cataloguing context and the main levels are work, expression, manifestation, and item.

"The entities in the first group represent the different aspects of user interests in the products of intellectual or artistic endeavour. The entities defined as work (a distinct intellectual or artistic creation) and expression (the intellectual or artistic realization of a work) reflect intellectual or artistic content. The entities defined as manifestation (the physical embodiment of an expression of a work) and item (a single exemplar of a manifestation), on the other hand, reflect physical form." (International Federation of Library Associations and Institutions 13)

While St Patrick's original works are unfortunately lost, there are several expressions of his epistles (editions and translations) that use a canonical numbering system $^{4}$ which becomes a physical reality in the manifestation and items of a particular edition or translation. In the FRBR context the manuscript witnesses are on the one hand expressions, manifestations and items of Patrick's work. Therefore, the

\footnotetext{
${ }^{4}$ Before the twentieth century two other systems were used, and Howlett introduced another text structure in the 1990s. However, none of these alternative text organisations are as widely used as White's chapter structure and numbering.
} 
canonical numbering for Patrick's work could be used. However, at the same time the manuscripts may be considered works in their own right and therefore it would also make sense to use another numbering system frequently used in a manuscript studies context following the physical topographic text structure and use folios and lines to locate sections within the text (Kalvesmaki). These are two different ways to approach the text of a manuscript and depending on a researcher's interest - either in the manuscript or the text it contains - either text structure can be a useful. In order to make the new documentary edition interoperable with the manuscript witnesses and text-critical editions, it was necessary to include information not only about the topographic structure, but also the canonical in the TEI transcriptions.

One downside of XML is that it enforces a hierarchical, tree-like document structure. Each XML document should have exactly one root element, and nested in it (or, to continue the tree analogy, 'branching off from it') are all other elements and text content (Fig. 1). However, such a hierarchical, tree-like document structure does not allow for the equal representation of the topographic and canonical text structure. The first requires the encoding of folios, columns and lines of the manuscripts while the second requires the encoding of the canonical chapters of White. This would certainly cause a nesting conflict as it is very likely that a canonical chapter starts on one folio, but ends on another and therefore the chapter could not be nested fully within an element representing a folio. Using overlapping markup is a violation of one of the central rules of XML: every XML element (besides the root element) has to be fully nested within another element and therefore it needs to be escaped somehow.
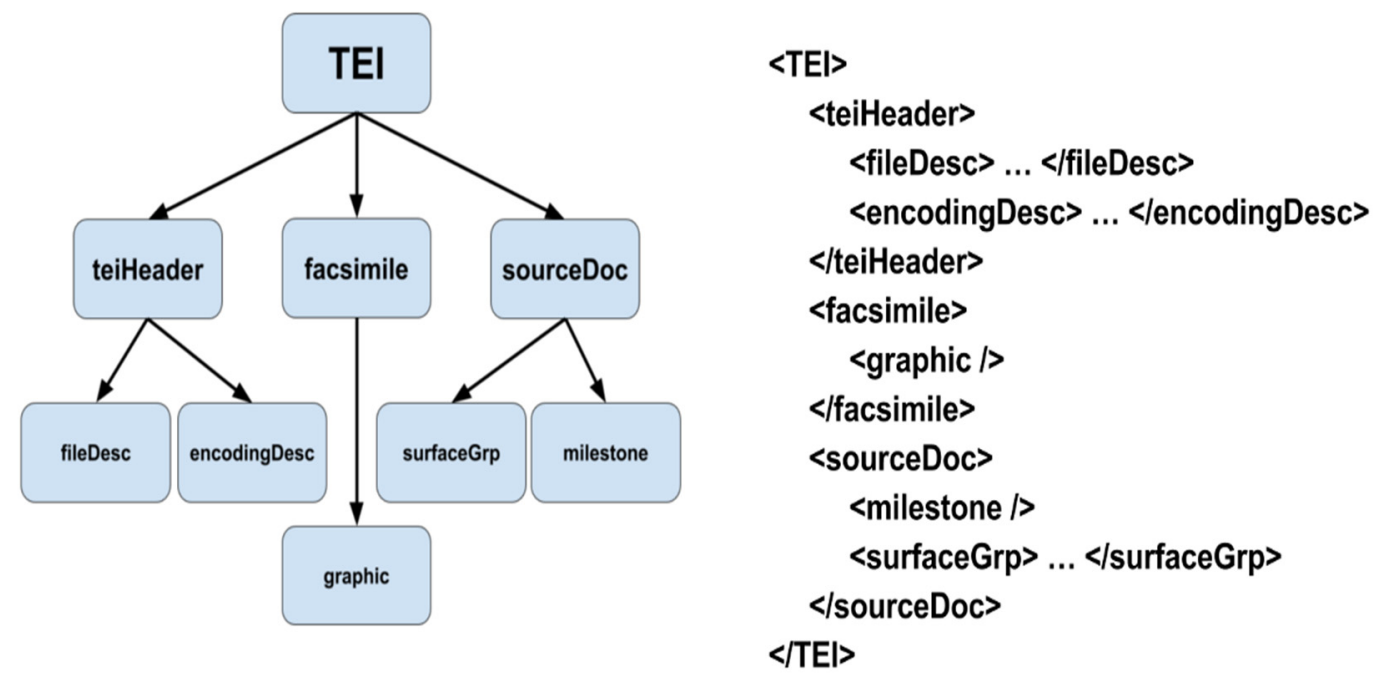

Fig. 1: The three top levels of the TEl model used for the transcriptions. Once represented as a treegraph (left) and once with the proper nesting highlighted by indentation (right). 
The issue of overlapping hierarchies is a common problem in TEI projects. TEI has its own Special Interest Group that works on solutions to overlapping hierarchy issues. ${ }^{5}$ Furthermore, the TEI guidelines contain a section named 'Non-hierarchical Structures' which advises possible workarounds to encode overlapping hierarchies in an XML-conform manner (20 Non-hierarchical Structures). Essentially the TEI guidelines suggest four ways to deal with data that leads to overlapping hierarchies in XML:

1. Multiple encoding of the same data, e.g., the different hierarchies should be modelled and transcribed separately;

2. The choice of one hierarchy as the main hierarchy, with others encoded using empty elements;

3. The fragmentation or segmentation of one or more hierarchies. In this case too one hierarchy is usually favoured as the main one;

4. Stand-off markup.

To encode the canonical chapters in the digital transcriptions of St Patrick's writings, the second method, empty elements, was chosen. The beginning and end of the canonical chapters was marked with the <milestone> element, an empty element that can be used to indicate a 'boundary point'. In an empty element no further child elements or text is allowed. To provide further information about what kind of structural feature is represented the attributes @type, @unit and @n are used on the <milestone> element and the attributes @xml:id and @spanTo are used to indicate how far a chapter goes. This kind of markup allows for the identification of what transcribed text belongs to what canonical chapter without violating the documentary encoding model.

In addition to provide more granular anchor points that can be used to compare the transcriptions on a line level with White's and Bieler's editions, the line and page numbers of White's edition were encoded with empty elements for line break $<|\mathrm{b} /\rangle$ and page break $\langle\mathrm{pb} />$. It is hoped that the inclusion of these features enables a maximum level of interoperability between the transcriptions, text-critical editions and translations. Furthermore, as each manuscript witness has a different text layout and structure, the canonical chapters and White's lines can be used as the basis for cross-version comparison and reference.

\section{Different presentations of the transcriptions}

A main benefit of TEI/XML encoded texts is that they can be used as source for a number of outputs. The new edition of St Patrick's epistles takes advantage of this by showing the transcriptions in different presentational views. As the TEI model of this project follows a documentary editing model the primary view presents the

\footnotetext{
${ }^{5}$ See: <https://wiki.tei-c.org/index.php/SIG:Overlap>.
} 
transcriptions following the layout of the manuscripts, a diplomatic view. It could be argued that such a diplomatic presentation is not useful as it simply tries to mimic the original manuscript. Facsimile images of the manuscripts are freely available on the Saint Patrick's Confessio Hypertext Stack website and interested people should simply look up the manuscript images. However, the digital diplomatic transcription have the benefit that they come with a lot of data that was encoded in the TEl. They are a research tool to explore the text structural features from the medieval manuscripts by utilizing the markup used for the encoding of capitals, highlighted letters, punctuation and spaces. For instance, this can be done in form of visual highlighting and overlay over the diplomatic transcriptions to show where in the text highlighted initials are preceded by punctuation (Fig. 2).

Another benefit of the digital documentary transcriptions is that they facilitate the study of 'scribal accidentals' that were encoded in the TEl such as additions, deletions and abbreviations. The TEl files can be used as the basis for visualization and automated analysis. In that way existing patterns can be spotted more easily which provides unique insight into the copying process of the individual scribes. For instance, a simple query shows how many deletions were made in a manuscript or what kind of abbreviations a scribe preferred.

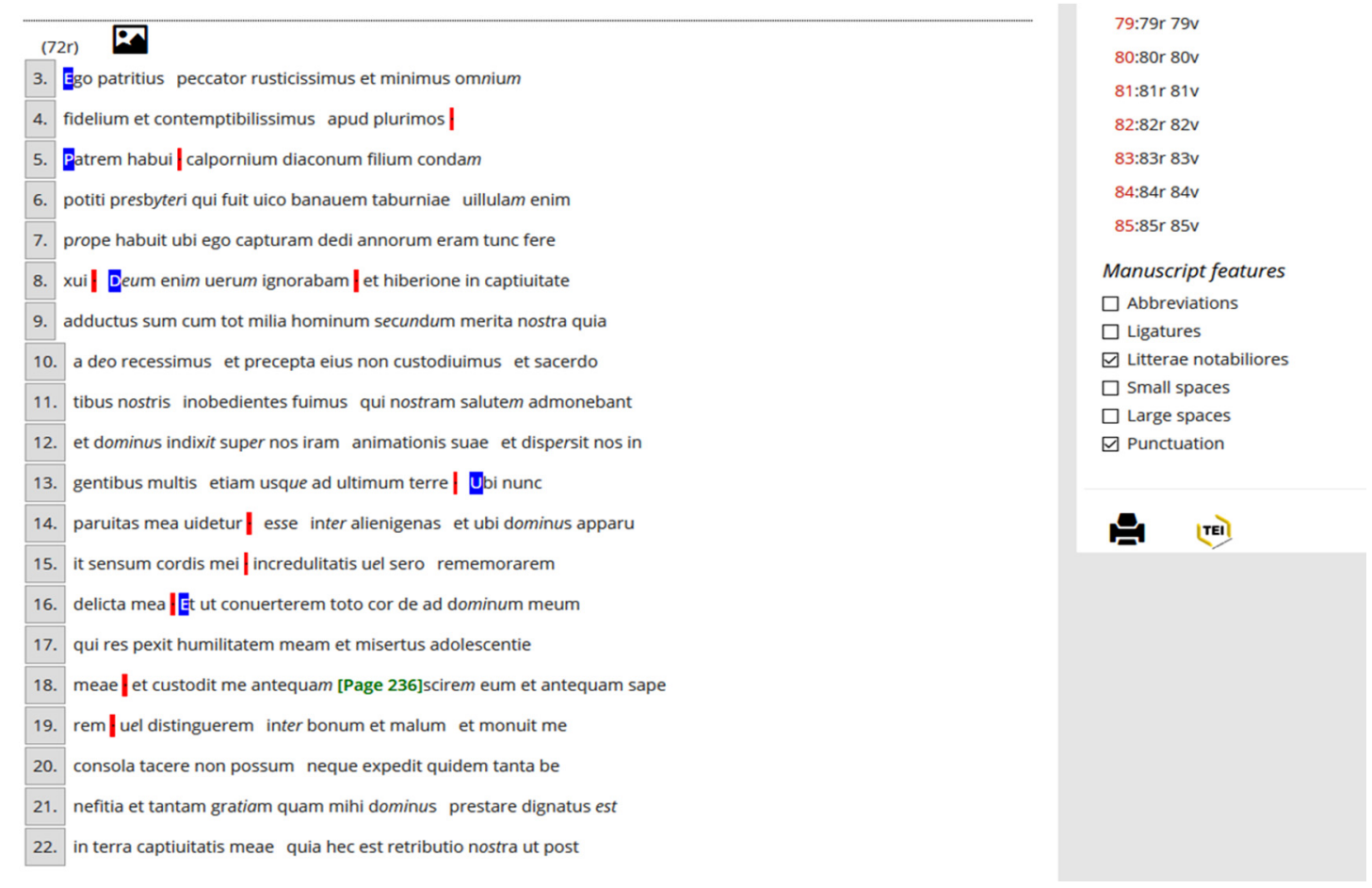

Fig. 2: Screenshot of the prototype of the digital documentary edition showing the transcription of folio $72 r$ of the Paris manuscript witness. Capital letters and punctuation are highlighted. 
Finally, the inclusion of White's canonical text structure allows for interaction with editions and translations that follow White's system. One way that shall facilitate this interaction is the presentation of the text of each transcription following the canonical chapters. In that way the reader can spot immediately where in a manuscript text is missing. Even if the text is missing hyperlinks corresponding to White's pages and line numbers are present that allow to explore what is written at this point in the other manuscripts. In this presentation the canonical structure can easily be compared across all manuscript witnesses and a user can explore missing passages and textual variation. For instance, a user can immediately see the big sections of text missing in the Dublin Confessio in the Book of Armagh (Fig. 3), the missing folios of the Arras manuscript or what parts of text are damaged in the Rouen manuscript which was the victim of a fire. \\ [4]et alia nocte nescio deus | scit utrum in me an iuxta me [5]uerbis | peritissime quos ego audiui et non potui intel | legere \\ nisiN [6]ad posterum orationis sic efficiatus est | qui dedit animam suam pro te [7]ipse est qui | loquitur in te et sic ex pertus \\ [8]et iterum uidi in me ipsum orantem | et eram quasi intra [9]corpus meum et audiui hoc est | super interiorem hominem [10]et \\ ibi fortiter orabat | gemitibus et inter haec stupebam et ammirabam [11] et co | gitabam quis esset qui in me orabat sed ad pos | \\ tremum [12]orationis sic efficiatus est ut sit episco | pus et sic expertus sum [13]recordatus sum apostolo | dicente spiritus \\ adiuuat infirmitates orationis | nostrnt [14]nam quod oremus sicut oportet nescimus sed ipse | spiritus [15]postulat pro nobis \\ gemit;bus inerrabilibus quae uer I bis expremi non [16]possunt et iterum dominus aduocatus noster I postulat pro nobis

Fig. 3: Screenshot of the prototype of the digital documentary edition showing the transcription of the Dublin manuscript following the canonical text structure. This view clearly shows that in this manuscript the text of three chapters $(26,27,28)$ of St. Patrick's Confessio are missing.

The new edition also tries to use existing online resources by linking to them. For instance, it does not contain any images of the manuscript witnesses, because high-resolution images are already available online on the Saint Patrick's Confessio Hypertext Stack. Instead of reproducing these images in the diplomatic view each 
folio provides a link the digital facsimile on the Saint Patrick's Confessio Hypertext Stack. Similarly are all markers of the canonical chapters in the canonical view linked to the same chapter in the electronic version of Bieler's text-critical edition (with three apparatus) on the Saint Patrick's Confessio Hypertext Stack. In that way a user of the new edition can also take advantage of the already existing digital resources about Patrick and the manuscript witnesses provided by this Royal Irish Academy project.

\section{Conclusion}

This article discussed the rationale behind the documentary editing of the manuscript witnesses of St Patrick's epistles and some features of the new digital documentary edition currently being developed. While in the last two hundred years several text-critical editions of Confessio and Epistola were produced, a digital documentary edition is something new and was still missing. Such an edition is necessary as important text-structural questions have been raised about Confessio and Epistola in the last decades and in order to bring these discussion to the next level a close study of the actual manuscript evidence together with existing editorial suggestions is crucial.

The digital documentary edition was designed for two main purposes: Firstly, to allow a close study of individual manuscript witnesses, their layout and text-structural features and 'scribal accidentals'. Secondly, to function as a mediator between the manuscripts and text-critical print editions and translations. For this second goal features from White's canonical edition were included into the TEI encoded transcriptions such as canonical chapters. As was shown, trying to model the manuscript layout and canonical chapter in the same TEI/XML document cannot be done in the same way as this would violate the XML nesting rule. The paper also discussed how this issue was escaped using empty elements.

The new digital edition comes with a number of benefits provided by the underlying TEI data model. First and foremost, providing a tool for automated study of the text structure of the individual manuscript witnesses and various scribal activities in the manuscripts which will lead to a better understanding of these documents and how they were produced by medieval scribes. An additional benefit of TEI/XML is that it can be transformed into any number of visualisations and views. A diplomatic and a canonical view will be possible access points for a user to explore the manuscripts and make cross-comparisons between the manuscript witnesses and other editions of the texts. In that way the new edition understands itself as a research tool that between the manuscripts, editions and translations based on the canonical text structure. Consequently, through the new documentary edition, St Patrick's Confessio and Epistola can be researched in ways that have never previously been possible. 


\section{Works Cited}

Bleier, Roman. Encoding St Patrick's epistles: history and electronic editing of the manuscript witnesses. Dissertation, University of Dublin, Trinity College, 2016.

Bleier, Roman. "Re-Examining the Function of St Patrick's Writings in the Early Medieval Tradition." Proceedings of the Royal Irish Academy. Section C: Archaeology, Celtic Studies, History, Linguistics, Literature, vol. 116C, 2016, pp. 95-117, www.jstor.org/stable/10.3318/priac.2016.116.07. Accessed 11 April 2017.

Binchy, D. A. "Patrick and His Biographers: Ancient and Modern." Studia Hibernica, no. 2, 1962, pp. 7-173, www.jstor.org/stable/20495717. Accessed 11 April 2017.

Dumville, David N. "The form of St Patrick's Confessio in the 'Book of Armagh'." Saint Patrick, AD 493-1993, edited by D.N. Dumville et al., Boydell, 1993, pp. 191-202.

Gabler, Hans Walter. "The primacy of the document in editing." Ecdotica, vol. 4, 2007, pp. 197-207.

Gwynn, John. Liber Ardmachanus = The Book of Armagh. Hodges, Figgis \& Co. Limited and Williams \& Norgate, 1913.

Hood, A.B.E. St. Patrick: his writings and Muirchu's life. Phillimore, 1978.

International Federation of Library Associations and Institutions. Functional Requirements for Bibliographic Records. 2009, https://www.ifla.org/files/assets/cataloguing/ frbr/frbr_2008.pdf. Accessed 11 April 2017.

Kalvesmaki, Joel. "Canonical References in Electronic Texts: Rationale and Best Practices." Digital Humanities Quarterly, vol. 8, no. 2, 2014, http://www.digitalhumanities.org/ dhq/vol/8/2/000181/000181.html. Accessed 11 April 2017.

O'Loughlin, Thomas. Discovering Saint Patrick. Paulist Press, 2005.

Patrick. "Confession et lettre à Coroticus." Edited by R.P.C. Hanson, Sources chrétiennes, vol. 249, 1978.

Patrick. Liber Epistolarum Sancti Patricii Episcopi = The book of letters of Saint Patrick the bishop. Edited by D.R. Howlett, Four Courts Press, 1994.

Patrick. Libri epistolarum sancti Patricii episcopi. Edited by Ludwig Bieler, vol. 1, Irish Manuscripts Commission, 1952.

Pierazzo, Elena. "A rationale of digital documentary editions." Literary and Linguistic Computing, vol. 26, no. 4, 2011, pp. 463-477.

Pierazzo, Elena. "Digital Documentary Editions and the Others." The Annual of the Association for Documentary Editing, vol. 35, 2014, http://scholarlyediting.org/ 2014/essays/essay.pierazzo.html. Accessed 11 April 2017.

Pierazzo, Elena and Peter Stokes, "Putting the text back into context: a codicological approach to manuscript transcription." Kodikologie und Paläographie im digitalen Zeitalter, vol. 2, edited by F. Fischer, C. Fritze and G. Vogeler, Books on Demand, pp. 397-429. 
Saenger, Paul. Space between Words: The Origins of Silent. Stanford University Press, 1997.

Sharpe, Richard, "Palaeographical considerations in the study of the Patrician documents in the Book of Armagh." Scriptorium, vol. 36, 1982, pp. 3-28.

White, Newport J. D. "Libri Sancti Patricii: The Latin Writings of Saint Patrick." Proceedings of the Royal Irish Academy. Section C: Archaeology, Celtic Studies, History, Linguistics, Literature, vol. 25, 1904, pp. 201-i., www.jstor.org/stable/25502726.

White, Newport J. D. "The Paris Manuscript of St. Patrick's Latin Writings." Proceedings of the Royal Irish Academy. Section C: Archaeology, Celtic Studies, History, Linguistics, Literature, vol. 25, 1904, pp. 542-552, www.jstor.org/stable/25502730. Accessed 11 April 2017.

\section{Electronic Sources}

"20 Non-hierarchical Structures." P5: Guidelines for Electronic Text Encoding and Interchange, Version 3.1.0, Last updated on 15th December 2016, http://www.teic.org/release/doc/tei-p5-doc/en/html/NH.html. Accessed 5 May 2017.

P5: Guidelines for Electronic Text Encoding and Interchange, Version 3.1.0, Last updated on 15th December 2016, http://www.tei-c.org/release/doc/tei-p5-doc/en/html/. Accessed 5 May 2017.

Medieval Unicode Font Initiative (MUFI). http://folk.uib.no/hnooh/mufi/. Accessed 5 May 2017.

Saint Patrick's Confessio Hypertext Stack. The Royal Irish Academy, 2011, http://www.confessio.ie/. Accessed 5 May 2017. 